\title{
UN CASO DE VIOLACIÓN DEL ART. 8 DEL CONVENIO EUROPEO PARA LA PROTECCIÓN DE LOS DERECHOS HUMANOS Y DE LAS LIBERTADES FUNDAMENTALES POR PASIVIDAD DE LA ADMINISTRACIÓN. COMENTARIO A LA SENTENCIA DEL TRIBUNAL EUROPEO DE DERECHOS HUMANOS EN EL CASO SALECK BARDI CONTRA ESPAÑA
}

\author{
Marcela Acuña San Martín \\ Profesora de Derecho de Familia \\ Universidad de Talca
}

Sumario: I. Presentación. II. Los hechos. III. El conflicto sometido a la decisión del TEDH. IV. La norma y los principios. V. Lo resuelto por el Tribunal. VI. Conclusiones.

\section{Presentación}

La sentencia que paso a comentar ${ }^{1}$, además de reciente, reviste interés por cuanto el Tribunal Europeo de Derechos Humanos (TEDH) proporciona en ella un corolario de su doctrina sobre la interpretación del art. $8^{\circ}$ del Convenio para la Protección de los Derechos Humanos y de las Libertades Fundamentales (en adelante el "Convenio"). Doctrina que se ha ido consolidando con los años por medio de una serie de distintas resoluciones, pero que en ésta el Tribunal asienta, integra y reafirma; por ello constituye una sentencia, que sin perjuicio de otras destacadas, merece ser comentada, al ofrecer una mirada clara y global de aquello que constituye la esencia de la vida familiar bajo la perspectiva del art. $8^{\circ}$ del Convenio y así como de la extensión y alcance de las obligaciones que en su virtud se imponen a los Estados.

\section{LOS HECHOS}

Dentro de una secuencia alambicada, los hechos más relevantes del caso para lo que aquí interesa, resumidamente son:

\footnotetext{
${ }^{1}$ Sentencia de 24 de mayo de 2011 en asunto Saleck Bardi c. España, iniciado por demanda No 66167/09.
} 
En el verano de 2002, la hija de la demandante, Saltana, nacida el 31 de diciembre de 1992, llegó a España procedente de los campamentos de refugiados saharauis de Tindouf para una estancia de dos meses, dentro del marco del programa de vacaciones organizado por la Federación de Asociaciones de Amigos del Pueblo Saharaui, entidad privada sin ánimo de lucro. La niña residía desde 2001 en Tindouf, donde su madre la había dejado a la edad de seis años, al cuidado de otra persona. A su llegada a España fue albergada en una familia de acogida.

La estancia, que debía terminarse el 9 de septiembre de 2002, fue prolongada por razones médicas: la niña padecía de una afección hepática. La federación responsable de la estancia de la niña en España solicitó la prórroga oficial de ésta ante el Servicio de Protección de Menores de la Dirección General de Familia del Gobierno de la Región de Murcia, pero no obtuvo respuesta de la Administración.

El 29 de marzo de 2004, dieciséis meses después, la Dirección General de Familia fue informada de que la demandante reclamaba el regreso de su hija a los campamentos de refugiados de Tindouf. El Servicio de Protección de Menores de la Región de Murcia inició entonces un procedimiento con el fin de determinar la evolución del estado de salud de la menor. En dicho proceso en reiteradas oportunidades la familia de acogida había rechazado entregar a la menor a la Administración para su retorno con su madre.

El 11 de mayo de 2004, el Servicio de protección de menores declaró a la niña en situación de desamparo y, en aplicación del procedimiento de urgencia, la sometió a su tutela y decidió ingresarla en la unidad de observación y acogida de un centro para menores "para su traslado a los campamentos de refugiados de Tindouf con su madre”. La familia de acogida impugnó esta resolución ante el Juzgado de familia No 9 de Murcia. El Juez no tuvo como parte a los demandantes por falta de legitimación para actuar. La familia de acogida apeló esta decisión ante la Audiencia Provincial de Murcia, la que estimó el recurso.

Por una sentencia del 19 de septiembre de 2005, el Juzgado de familia No 9 de Murcia suspendió provisionalmente la tutela asumida por el Servicio de Protección de Menores y otorgó la custodia de Saltana a la familia de acogida. En su motivación, precisó:

“(...) esta medida se mantendrá hasta que a la menor se le realicen todos los análisis necesarios que ayuden a conocer la etiología de su enfermedad, haya 
recibido todos los controles y tratamientos adecuados de la misma y sea dada su alta médica (...) para que pueda regresar a su país de origen recibiendo en el mismo el seguimiento médico oportuno (...). Transcurrido este periodo de tiempo, su tutela volverá a ser asumida por la Dirección General de Familia y Servicios Sociales para su devolución a su familia biológica o de origen".

Este auto fue dictado sin que la demandante fuera informada del procedimiento en curso y, en consecuencia, sin que hubiera tenido la posibilidad de comparecer o de intervenir.

El 5 de junio de 2006, la demandante viajó a España y solicitó al Gobierno de la Región de Murcia la restitución de su hija. Compareció con este fin ante el Juzgado de familia No 9 de Murcia, encargado del procedimiento, y pidió intervenir como parte. Su solicitud fue aceptada por decisión del 7 de diciembre de 2006. En el momento de su comparecencia, la demandante sostuvo no haber tenido conocimiento de la enfermedad de su hija y no haber sido prevenida de que se quedaba en España tres meses después del supuesto fin de su estancia. Declaró haber comenzado a reclamar el regreso de su hija en esa fecha, sin obtener respuesta.

Por resolución del 30 de abril de 2007 el Juzgado de familia No 9 de Murcia decidió otorgar a la familia de acogida la tutela de la menor con fundamento, entre otras razones, en que ésta, entonces con 15 años de edad, había manifestado su deseo de quedarse con tal familia y había declarado haber estado sometida a esclavitud en los campamentos de refugiados. Resaltó, por otro lado, los numerosos fallos de la Administración en el desarrollo del procedimiento, señalando lo siguiente:

“(...) Entiendo que en este caso, han fallado clamorosamente las Administraciones Públicas competentes para tomar decisiones en estos casos de llegada temporal a España de menores extranjeros no acompañados. No se puede tener a una menor, apatrida además, casi cinco años en una situación indefinida. (...) en septiembre de 2002 la entidad pública debió asumir la tutela de la menor por desamparo, delegando la guarda en los que de hecho la ostentaban, haciendo un seguimiento exhaustivo de la enfermedad, y contactando con la Delegación del Gobierno para intentar la repatriación. Y ello porque pasados nueve meses (plazo vencido en mayo de 2003), se le tenía que haber otorgado la autorización de residencia. En lugar de ello, la resolución que aprecia el desamparo no se dictó hasta el 11 de mayo de 2004. (...) La pasividad de las Administraciones Públicas competentes en la materia ha dejado a la menor en una especie de "limbo jurídico" (...) 
Las concurrencia de los requisitos legales parece evidente: cinco años después, la menor se encuentra en una situación legal, desamparada tres años y luego suspendida tal medida para la práctica de unas pruebas médicas que pudo y debió llevar a cabo en septiembre de 2002 la Entidad Pública. Una menor no puede estar en tal situación por la desidia burocrática de los poderes públicos, sin nacionalidad y sin permiso de residencia, vulnerando toda la normativa internacional e interna en la materia.

(...) Hay un matrimonio que lleva cinco años cuidando bien de la menor, y por ello (y en aras a su supremo interés, que prevalece sobre cualquier otro) procede constituir la tutela ordinaria (...)".

La demandante apeló la resolución y solicitó la práctica de determinadas pruebas. El 31 de octubre de 2007, la Audiencia provincial de Murcia aceptó que la menor fuera sometida a un examen psicológico. La petición relativa a las otras pruebas fue rechazada. La demandante impugnó. Por un auto del 7 de marzo de 2008, la Audiencia provincial estimó parcialmente el recurso presentado por la demandante y aceptó la práctica de una parte de las otras pruebas propuestas (los testimonios de la menor, de sus tutores y de su madre biológica), y rechazó la solicitud de otras pruebas testificales, considerándolas sin relación con la cuestión debatida.

Por un auto del 30 abril 2008, la Audiencia Provincial de Murcia desestimó la apelación de la demandante y confirmó la concesión de la tutela a la familia de acogida, al primar el interés de la niña sobre el de la demandante, que no había demostrado que se hubiera preocupado por la situación de su hija desde que la mandó desde Mauritania a los campamentos de Tindouf en Argelia, sin haber hablado nunca con ella. Observa la Audiencia que la declaración realizada por la niña después de su encuentro con la demandante revelaba que se negaba a irse de nuevo con esta última, que la había abandonado, según sus propias declaraciones, a los seis años. El informe psicológico precisaba que la menor quería continuar viviendo en España debido a los vínculos afectivos que había establecido con su familia de acogida desde 2002 y del sentimiento de abandono que mostraba frente a su madre. La demandante declaró que no quería obligar a su hija a seguirla a su país y que comprendía que su vida estaba en España, razón por la cual no fueron practicadas otras pruebas. Por consiguiente, la Audiencia provincial concluye que no era razonable obligar a una adolescente de quince años a regresar a casa de su madre, a la que no veía desde los seis años, hacia la que no mostraba ningún afecto y no compartía su lengua, habiendo sido necesario un intérprete en 
el momento de su encuentro, más cuando el informe psicológico establecía que la menor estaba bien integrada en su familia de acogida.

Invocando el artículo 24 (derecho a la tutela judicial efectiva) de la Constitución española, la demandante presentó un recurso de amparo ante el Tribunal Constitucional. Impugnaba la inadmisión por la Audiencia provincial de Murcia de ciertas pruebas que ella había propuesto en apelación y alegaba que la tutela de su hija había sido concedida a la familia de acogida sin que ella hubiese sido oída en el procedimiento. El Tribunal Constitucional inadmitió el recurso por una resolución del 1 de junio de 2009, notificada el 15 de junio de 2009, por falta de relevancia constitucional de las quejas presentadas.

\section{EL CONFLICTO SOMETIDO A LA DECISIÓN DEL TEDH}

La demandante, una mujer de origen saharaui, se quejaba de haber sido privada, por órganos del gobierno español, de la tutela de su hija sin haber podido intervenir en el procedimiento. Alegaba una vulneración de su derecho a un proceso equitativo y al respeto a su vida familiar garantizados por los artículos $6^{\circ}$ y $8^{\circ}$ del Convenio. La demandante era consciente de que el regreso de su hija a Argelia no era deseable para la estabilidad emocional de ésta, pero pidió al Tribunal reconocer las irregularidades acaecidas en el procedimiento interno con el fin de impedir que una situación como la suya se reproduzca para otras madres saharauis ${ }^{2}$. Invoca también el art. 13 del mismo Convenio.

La demandante indica que, por el auto del 30 de abril de 2007, confirmado en apelación, el Juzgado de familia había decido otorgar de oficio la tutela a la familia de acogida de la niña, frente a la pasividad de las autoridades, que habían tardado dos años en declarar la situación de desamparo y luego tres años más para decidir que había que efectuar exámenes médicos antes de su

\footnotetext{
2 En cuanto al procedimiento en apelación, la demandante mantuvo que ciertas pruebas solicitadas por ella no fueron practicadas, lo que le causó perjuicio, cuestión a la que no me voy a referir, sin perjuicio de señalar, en lo medular, que el Tribunal estimó que la motivación aducida para rechazar las pruebas propuestas y no admitidas, no parece arbitraria y se revela suficiente. A este respecto, recuerda que la admisibilidad de las pruebas depende, en primer lugar, de las reglas del derecho interno y que corresponde, en principio, a las jurisdicciones nacionales apreciar los elementos de prueba practicados por ellas. El Tribunal observa que la decisión se adoptó con apoyo en las numerosas pruebas recogidas en el marco de un procedimiento en el que la demandante estaba representada por un abogado y no apreció, en consecuencia, ningún fallo imputable a las jurisdicciones internas a este respecto.
} 
eventual devolución. La demandante juzga cuanto menos sorprendente, que tal medida hubiera sido adoptada sin oírla incluso cuando se encontraba en España para volver con su hija a Tindouf. Los principios de contradicción y de igualdad de armas no habrían sido respetados, en su opinión.

La demandante hace valer que la concesión de la tutela de su hija a la familia de acogida implica en la práctica su pérdida, en la medida en que no tiene medios económicos para desplazarse a visitarla en Murcia y tardó cuatro años en resolver las dificultades administrativas para viajar a España, donde pudo sobrevivir gracias a la ayuda de la Asociación de Amigos del Pueblo Saharaui de Cartagena. En fin, sostiene que el hecho de reconocer ante los jueces que las condiciones de vida son mejores en España que en Tindouf y que el traslado de su hija a los campamentos sería perjudicial para ella, no justifica la ausencia de violación del Convenio, ya que perdió a su hija como si hubiese fallecido.

El Gobierno, por su parte, subrayó en primer lugar, que el procedimiento de adopción de medidas de protección de menores tiene como fin el interés de éstos. A su juicio, el juez puede, por tanto, adoptar cualquier medida que considere necesaria en interés de un menor, incluso si no es solicitada por las partes, sin que su imparcialidad se vea por ello comprometida.

El Gobierno expone que las autoridades internas adoptaron primeramente medidas provisionales (poner a la menor bajo la tutela de la autoridad pública) conformes al Convenio con el fin de "proceder posteriormente al traslado de la niña con su madre a los campamentos de refugiados saharauis en Tindouf". El traslado no se habría efectuado debido al estado de salud de Saltana. La tutela de ésta habría sido confiada luego a su familia de acogida española, lo que estaría justificado por el interés superior de la niña. En su resolución del 30 de junio de 2008, la Audiencia provincial habría considerado a este respecto las declaraciones de Saltana, entonces con 15 años, y las de su madre y contó con el informe técnico y psicológico adecuado. En cualquier caso, la madre de Saltana no habría sido privada de la relación parental y podría mantener contacto con su hija si lo deseara. La Audiencia provincial no habría fijado régimen de visitas, pero podrían efectuarse visitas si la demandante lo pidiera, lo que no habría sido el caso hasta el momento.

Señala, además, que los lazos familiares entre Saltana y su madre no se rompieron debido a la llegada de la niña a España, sino que estaban rotos antes, habiendo vivido la demandante en Mauritania y no con su hija en los campamentos de Tindouf en Argelia. La demandante misma habría reconocido, 
por otra parte, ante la Audiencia provincial, que tenía interés en que su hija continuara viviendo en España con su familia de acogida que asumía la tutela. Teniendo en cuenta el interés superior de la niña, su grado de integración en su medio familiar en España, la ruptura previa de su vida común con su madre y la naturaleza de la tutela, que preserva el derecho de la demandante a ver a su hija, el Gobierno concluye que la alegación de vulneración del artículo $8^{\circ}$ del Convenio carece de fundamento.

\section{LA NORMA Y LOS PRINCIPIOS}

El Tribunal estimó que las quejas de la demandante debían ser examinadas bajo la perspectiva del art $8^{\circ}$ del Convenio, por estar todas estrechamente vinculadas a él.

Prescribe el art. $8^{\circ}$ :

"1. Toda persona tiene derecho al respeto de su vida privada y familiar, de su domicilio y de su correspondencia.

2. No podrá haber injerencia de la autoridad pública en el ejercicio de este derecho salvo cuando esta injerencia esté prevista por la ley y constituya una medida que, en una sociedad democrática, sea necesaria para la seguridad nacional, la seguridad pública, el bienestar económico del país, la defensa del orden y la prevención de las infracciones penales, la protección de la salud o de la moral, o la protección de los derechos y las libertades de terceros".

Sobre el contenido esencial y alcances de la noción de vida familiar y los principios emanados del art. $8^{\circ}$, es posible precisar, conforme a la jurisprudencia constante del Tribunal, reafirmados en esta sentencia, que:

- El artículo $8^{\circ}$ tiene esencialmente por objeto proteger al individuo contra las injerencias arbitrarias de las autoridades públicas, pero no se limita a imponer al Estado que se abstenga de injerencias arbitrarias, sino que a este compromiso sobre todo negativo pueden añadirse obligaciones positivas inherentes a un respeto efectivo de la vida privada o familiar. Estas obligaciones pueden implicar la adopción de medidas dirigidas al respeto de la vida familiar incluso en las relaciones de los individuos entre sí.

- Tanto en un caso como en el otro (obligaciones negativas y positivas de los Estados), hay que considerar el justo equilibrio entre los intereses concurrentes del individuo y de la sociedad en su conjunto; incluso, en ambas hipótesis, el Estado goza de cierto margen de apreciación. 
- El Tribunal reitera el principio bien establecido en su jurisprudencia según el cual, el fin del Convenio consiste en proteger derechos concretos y efectivos. En esta lógica, un respeto efectivo de la vida familiar impone que las relaciones futuras entre progenitor e hijo se ajusten sobre la única base del conjunto de los elementos pertinentes, y no por el simple paso del tiempo.

- La relación entre un padre y un hijo forma parte de la vida familiar, por tanto, la relación entre la demandante y su hija forma parte de la vida familiar en el sentido del artículo $8^{\circ}$ del Convenio, aunque estén separadas de facto al menos desde la llegada a España de la hija de la demandante durante el verano de $2002^{3}$. El Tribunal recuerda a este respecto que, para un progenitor y su hijo, estar juntos representa un elemento fundamental de la vida familiar ${ }^{4}$.

- Las obligaciones negativas que el art. $8^{\circ}$ impone a los Estados consisten en abstenerse de injerencias arbitrarias, exigiendo, en esta parte que la toma de decisiones que desemboca en medidas de injerencia sea equitativa y respete, debidamente, los intereses protegidos por la disposición. No toda injerencia en la vida privada y familiar está prohibida; expresamente la disposición permite injerencias prevista por la ley y que constituyan una medida que, en una sociedad democrática, sea necesaria para la seguridad nacional, la seguridad pública, el bienestar económico del país, la defensa del orden y la prevención de las infracciones penales, la protección de la salud o de la moral, o la protección de los derechos y las libertades de terceros.

- Desde el punto de vista positivo, el art. $8^{\circ}$ impone a los Estados la obligación de adoptar medidas adecuadas para que un progenitor pueda reunirse con sus hijos. El Tribunal recuerda que, en los asuntos que afectan a la vida familiar, la ruptura del contacto con un niño pequeño puede conducir a una alteración creciente de su relación con su progenitor, por ello el artículo $8^{\circ}$ implica el derecho de un progenitor a medidas adecuadas para reunirse con su hijo y la obligación para las autoridades nacionales de adoptarlas. No obstante, la obligación para las autoridades nacionales de tomar medidas al respecto

\footnotetext{
${ }^{3}$ Alguna evolución se presenta en esta parte respecto de la doctrina que entendía que la apreciación de la realidad de una "vida familiar" que legitime la invocación del precepto exigía la presencia de un vínculo preexistente, efectivo, y que implique una relación lo suficientemente real y estrecha entre los sujetos implicados, considerado, entre otros, en Salanova, Marta, 1995, "El derecho del menor a no ser separado de sus padres", en Revista Derecho Privado y Constitución, No 7, España, p. 264.

${ }^{4}$ El derecho de relación entre padres e hijos, aun cuando los primeros estén privados de la patria potestad, aparece reconocido en sede general, expresamente en el art. 160 del Código civil español.
} 
no es absoluta, porque puede ocurrir que la reunión de un progenitor con sus hijos no pueda efectuarse inmediatamente y requiera de preparativos. La naturaleza y la extensión de éstos dependen de las circunstancias de cada caso, pero la comprensión y la cooperación del conjunto de las personas concernidas constituyen siempre un factor importante. ¿Cuándo estamos en presencia de "medidas adecuadas"? ciertamente se trata de una proposición abierta, ambigua, indeterminada, que el propio Tribunal se ha encargado de precisar: Para ser adecuadas, las medidas dirigidas a reunir al progenitor y a su hijo deben ser adoptadas rápidamente, porque el paso del tiempo puede tener consecuencias irremediables para las relaciones entre el niño y los progenitores que no viven con él. A partir de ahí, la celeridad de la decisión es un criterio de corrección de la adecuación de la medida al caso concreto.

- En la hipótesis en la que los contactos con los progenitores corren peligro de amenazar los intereses o de atentar contra los derechos de los menores, corresponde a las autoridades nacionales velar por un justo equilibrio entre ellos.

- Por último, el art. $8^{\circ}$ impone una carga más a los Estados: a cada Estado contratante le corresponde dotarse de los instrumentos jurídicos adecuados y suficientes para asegurar el respeto de las obligaciones positivas que le incumben en virtud del artículo $8^{\circ}$ del Convenio. El Tribunal se limita a verificar si, en la aplicación y la interpretación de las disposiciones legales pertinentes, las autoridades nacionales han respetado las garantías del artículo $8^{\circ}$, teniendo particularmente en cuenta el interés superior de los menores.

El punto decisivo en el caso Saleck Bardi contra España consiste, entonces, en saber si las autoridades nacionales tomaron todas las medidas necesarias y adecuadas que se podían razonablemente exigir para facilitar el regreso de la niña junto a su madre en el menor plazo posible. El TEDH se limita, por tanto, a examinar si, en este caso, las medidas adoptadas por las autoridades españoles para regularizar la situación de alegal de Saltana en España, y para garantizar los derechos de la demandante fueron adecuados y suficientes desde el punto de vista material. Dicho de otro modo, le toca examinar si las autoridades españolas actuaron en desconocimiento de las obligaciones positivas que emanan del artículo $8^{\circ}$ del Convenio.

\section{LO RESUELTO POR EL TRIBUNAL}

El Tribunal señala que, en su auto del 30 de abril de 2007 dictado en el marco de la ejecución de la sentencia del 19 de septiembre de 2005, el Juzgado de familia No 9 de Murcia decidió actuar rápidamente considerando, 
principalmente, el interés de la menor y concedió la tutela de esta última a su familia de acogida en España, tras haber constatado numerosos fallos de la Administración durante el procedimiento. En su decisión del 30 de abril de 2007, el Juez expuso los motivos de la concesión de la tutela ordinaria a la familia de acogida de la menor de forma muy detallada, atendiendo a que Saltana estaba allí bien integrada. El Tribunal no percibe ningún elemento que permita dudar de la imparcialidad del Juzgado de familia por el hecho de dictar una decisión contra los intereses de la demandante.

Reiterando que no le corresponde sustituir con su apreciación a la de las autoridades nacionales competentes en cuanto a las medidas que habrían debido ser tomadas, porque estas autoridades están mejor situadas, en principio, para proceder a tal evaluación, y reconociendo que en este caso, las jurisdicciones internas intentaron de buena fe preservar el bienestar de Saltana, el TEDH constata la existencia de falta de diligencia en el procedimiento llevado a cabo por las autoridades responsables de la prolongación de la estancia de la menor en España. El Tribunal señala que Saltana continuó de facto en la familia de acogida después de la expiración de su estancia de dos meses en España. En efecto, ninguna respuesta fue dada por el Servicio de Protección de Menores a la Federación de Asociaciones de Amigos del Pueblo Saharaui en tanto que responsable de la presencia de Saltana en España, cuando solicitó, el 9 de septiembre de 2002, la prolongación oficial de la estancia de la niña por razones de salud. No es sino hasta el 11 mayo de 2004 cuando el Servicio de protección de menores declaró a la niña en situación de desamparo y, en aplicación del procedimiento de urgencia, la puso bajo su tutela para supervisar la evolución de su estado de salud y proceder a su traslado a Tindouf. Esta decisión se produjo después de que la Dirección General de Familia fuera informada de que la demandante reclamaba el regreso de su hija. El TEDH constata a este respecto una pasividad total de las autoridades administrativas desde septiembre de 2002 a mayo de 2004, y señala que no ha sido avanzada ninguna explicación satisfactoria para justificar este plazo de cerca de dos años para que la Administración pusiera bajo su tutela a la menor, que no tenía entonces ningún permiso legal de estancia en España. Además, el TEDH verifica que no se impuso ninguna sanción a la familia de acogida, a pesar de su actitud obstruccionista y su reiterada negativa a devolver a la menor a los servicios pertinentes para facilitar su regreso con la madre biológica.

Por otra parte, se advierte que una sentencia del 19 de septiembre de 2005, dictada 16 meses después de la declaración de desamparo de la menor, el Juz- 
gado de familia suspendió provisionalmente la tutela de la Administración y concedió la custodia de Saltana a la familia de acogida, con la que permanecía de facto. La ejecución del auto del 11 de mayo de 2004 para ingresar a Saltana en un centro de menores bajo la tutela de la Administración, había sido dejado entre tanto en suspenso mientras no fueran practicados los exámenes médicos y, llegado el caso, los tratamientos médicos necesarios. El TEDH observa a este respecto que el auto no fijaba, sin embargo, el plazo para la realización de los exámenes y de los tratamientos indicados.

Diecinueve meses más tarde, el 30 de abril de 2007, el Juzgado dictó la decisión de conceder la tutela de la menor a la familia de acogida debido a su integración en ella, subrayando, por otra parte, las numerosas deficiencias de la Administración, que ya he indicado.

El TEDH considera que el paso del tiempo, consecuencia de la pasividad de la Administración y de la falta de coordinación entre los servicios competentes, contribuyó de manera decisiva a la integración de la menor en su familia de acogida y en su vida cotidiana en Murcia. A la vista de lo que precede, razona el TEDH que las autoridades nacionales españolas fallaron en la obligación de celeridad, particularmente exigible para este tipo de asuntos. En atención a estas consideraciones, y a pesar del margen de apreciación del Estado demandado en la materia, el TEDH concluye que las autoridades españolas no desplegaron los esfuerzos adecuados y suficientes para hacer respetar el derecho de la demandante al retorno de su hija, obviando así su derecho al respeto de la vida familiar garantizado por el artículo $8^{\circ}$ Convenio. Se produjo así violación del artículo $8^{\circ}$ del Convenio.

Respecto de los daños, la demandante reclamó 150.000 euros (EUR) por el daño moral que habría sufrido, reconoce no obstante que su hija está perfectamente integrada en España y que su repatriación a los campamentos de Tindouf implicaría separarla de su entorno actual para hacerla vivir en condiciones de vida muy duras, lo que, por tanto, no reclama. El Gobierno juzga excesiva la cantidad solicitada por la demandante y subraya la ausencia de cualquier vida familiar entre la interesada y su hija desde 2001. El TEDH estimó que la demandante ha sufrido, debido a la constatada vulneración, un daño moral que no puede ser reparado por la simple constatación de violación. Considera que procede conceder a la interesada 30.000 EUR en concepto de daño moral's.

\footnotetext{
${ }^{5}$ Respecto de la demanda de costas y gastos, en aplicación de la jurisprudencia constante del TEDH consistente en que un demandante sólo puede obtener el reembolso de sus gastos y costas en la medida
} 


\section{CONCLUSIONES}

En mi opinión, el Tribunal Europeo ha resuelto correctamente el asunto en una sentencia, bien explicada y categórica. No se trata, como en antaño, de la insuficiencia de las legislaciones internas para resguardar la vida familiar mediante la ausencia del reconocimiento de tales relaciones familiares, tampoco de la adopción de medidas frontales o intervenciones directas en una familia; sino de un no actuar los órganos administrativos en cumplimiento de los deberes que la ley interna les impone, con la suficiente diligencia para adoptar medidas que garanticen y faciliten el mantenimiento de la referida vida familiar entre una madre y su hija. La pasividad de la Administración (advertida por la Audiencia Provincial de Murcia) no sólo afectó el derecho de la madre a recuperar a su hija, sino el derecho de la menor a no ser separada de sus progenitores y a mantener relaciones personales y contacto directo con su madre, al tenor del art. $9^{\circ}$ de la Convención sobre Derechos del Niño, petrificando una situación de hecho -la separación de facto entre madre e hija- de modo irreversible.

$\mathrm{El}$ argumento de haber actuado en pos del interés superior del menor en este caso queda completamente inutilizado; las autoridades administrativas, protectoras de menores actuaron en total desconocimiento tanto del art. $8^{\circ}$ del Convenio afectando el goce efectivo de los derechos reconocidos en él, como del resguardo de aquel superior interés, que en ningún momento valoraron. Este interés superior acabo reclamando de la justicia el carácter definitivo de la separación, fruto de la integración de la menor en la familia de acogida.

Por último, y muy brevemente, resta señalar que la sentencia también avanza hacia una interpretación flexible respecto de la regla del agotamiento de las vías de recurso interno enunciada en el artículo 35 del Convenio que impone a un demandante la obligación de utilizar los recursos normalmente disponibles y suficientes en el orden jurídico interno para permitirle obtener reparación de las vulneraciones que alega antes de que éstas sean sometidas a los órganos del Convenio, con lo cual, los mecanismos del convenio revisten siempre carácter subsidiario en relación a los sistemas nacionales de garantía de los derechos humanos. En efecto, si bien la demandante no se refirió expre-

en que se encuentre establecida su realidad, su necesidad y el carácter razonable y al hecho de que la demandante no presentó ninguna nota de gastos ni de honorarios, el Tribunal desestimó la demanda. 
samente al artículo 18 de la Constitución Española ("Se garantiza el derecho al honor, a la vida privada y familiar y a la propia imagen") en el marco de su recurso de amparo ante el Tribunal Constitucional, el TEDH, observa, no obstante, que amparándose en el artículo 24 de dicha Constitución, la demandante alegaba expresamente una violación de su derecho a recuperar a su hija menor. Siendo así, el Tribunal consideró que, en sustancia, si se planteó esta queja desde la perspectiva del artículo $8^{\circ}$ del Convenio, relegando a segundo plano la cuestión de forma. 
